other sections relate to incomplete chapters which have already been published and these allow the completion of another nine chapters (lithium, sodium, potassium, zinc, rubidium, cadmium, cesium, platinum and bismuth). Now that more than half the text, in both number of elements and pages, is complete (chapters for more than fifty elements are now complete, or virtually so), much of the frustration caused by gaps is removed. The standard of production remains high.

D. G. Murchison

\section{Putting viruses together}

Morphogenesis of T-Even Bacteriophages. By B. F. Poglazov. Pp. vi+ 105. Monographs in Developmental Biology, Vol. 7. (Karger: Basel, London and New York, 1973.) 54 Sw.fr.; £7.85; $\$ 16.75$.

IN a monograph which might better be entitled "T4 structural proteins and their assembly", the author has attempted to integrate the extensive physical and chemical studies on the proteins of bacteriophage $\mathrm{T} 2$ from his laboratory with the genetic analysis of phage development which has come out of laboratories in Europe and the United States in the past ten years. The product is a review of the results of roughly 100 papers arranged according to the part of the phage structure whose assembly is being considered.

Of the seven chapters, the two principal ones are devoted to assembly of the head and tail of T4 and T2. The discussion of head morphogenesis is devoted to the inferences on form determination which can be drawn from genetic analyses of mutants in T4 head genes and the interesting experiments from Poglazov's own laboratory on structure formation from solubilised phage T2 head protein. Unfortunately, little mention is made of the work which has been published to elucidate the role of DNA in phage head formation, a subject of considerable recent controversy.

The assembly of the phage tail receives the longest treatment-fully half the book. Again most space is devoted to the work of Poglazov and his collaborators on dissociation and reassociation of tail tube and sheath protein.

A short and extremely dense chapter is devoted to tail fibre assembly. The brevity is unfortunate because the fibre assembly pathway is certainly the best example of a morphogenetic pathway in T4 asembly, and beautifully illustrates the complementary approaches of genetics, immunology, electron microscopy and biochemistry to problems of structure formation. But enough references are given to enable the interested reader to fill in the details for himself.

In his devotion to detail, Poglazov obscures some of the larger problems of phage morphogenesis. There is hardly any mention of the timing of phage development, regulation of quantities of various components synthesised, or of possible mechanisms of length or form determination.

Generally, the author's policy is to present observations and results without comment. The lack of synthesis will make for difficult reading for the uninitiated, and the lack of evaluation of published results will at times be misleading for those not already familiar with the difficulties of experimentation in the field. Michael K. Showe

\section{Weather satellites}

Climatology from Satellites. By E. C. Barrett. Pp. xii +418 . (London Methuen: London, May 1974.) £7.90.

THE idea of this book, if I have divined its origins aright, is to liven up the teaching of climatology in schoolsand, perhaps, to geographers in universities-by introducing the subject through the medium of satellite pictures, backed up by the analysis of other kinds of satellite data. Or it may be meant just to give a fresh view of the subject in this way. The 41 satellite photographs are the book's main attraction. Among the more impressive ones are several which show the frontal cloudsheets of the northern and southern hemispheres trailing till they meet in the equatorial convergence and one (plate 19), a half-month composite, which shows the cloudless zone along the equator in the Pacific extending from the Americas as far as $170^{\circ} \mathrm{E}$. It is a pity that the minimum brightness composite (plate 9) which gives a sample of the rendering of ice and snow and persistent cloud was chosen from the Antarctic summer.

The book is written for geographers; others may find it useful as a handy small guide to the early history of weather satellites, the data and issues which are now available, the symbols in common use on map analyses of satellite information and so on. Among its features are a table (on page 21) of the spatial resolution and frequency of various kinds of satellite observation, the list of routinely available average, minimum and maximum brightness maps and their uses (on pages 50-51) the long table (pages 87-92) on identification of cloud types from satellite photographs, the samples of infrared techniques for deriving surface and cloud-top temperatures, mean cloudiness and relative humidities and the introduction (on pages 111-7) to the derivation of precipitation from satellite surveys. More could have been said about the inadequacy of precipitation measurements at the surface, with the insoluble problems of representative catchment of the precipitation at sea and of snowfall anywhere, and the potential virtue of uniformity in derivations, however difficult and indirect, from satellite observations. We laarn (page 124) that most cloud bands in all latitudes are aligned with the surface wind; we learn also, however, the complications and limited possibilities of accuracy in deriving wind speeds and cloud-top heights.

But whether climatology can be taught in the way this book attempts it may be doubted. The effect is rather like that of walking into a cinema in the middle of the film: the order of presentation is strangely jumbled. We meet the gradient wind on pages 120-3, the sun as the source of energy on page 147 and are rewarded for patience with a nice set of pole-to-pole profile diagrams of the various components of the energy budget on page 159.

I hope not to be unfair in saying that I found this author's style foreign and difficult; for example the ambiguous statement on page 71 that: "the amplitudes and locations of the maxima and minima of incoming radiation are seasonally variable" (within a given season? from season to season? or when we compare the same season in different years?). The waves in the upper westerly winds are introduced (page 196) with the statement that they "undulate meridionally". The stratospheric circulation is explained (page 209), only too briefly, as "a huge standing wave related to the zone of maximum insolation": in this the book clearly attempts too much. Finally, the odd statement is made that an atlas of cloudiness might seem uninteresting except in relation to programmes of space research and Earth Resources Technology Satellites, though we are persuaded that the knowledge is needed for computer modelling and for tracing the general circulation of the atmosphere: surely the last named is the average viewer's first exciting impression of satellite cloud photography.

The author is an enthusiast for the use of satellite observations and has contributed valuable studies of the circulation and cloud development over the tropics, which occupy much of the regional climatology section of the book. Despite the irritating awkwardnesses, the book succeeds in communicating this enthusiasm and may therefore succeed also in stimulating the general reader to try out the use of this fascinating tool himself and seek further understanding. H. H. LAMB 